\title{
Citizen Participation in the Development of the Regional Public Management
}

\author{
Ye Yazhen $^{1 *}$ Liu Hong ${ }^{2}$ \\ ${ }^{1,2}$ School of Public Management, Yunnan University of Finance and Economics, \\ Kunming, 650221, P.R China, \\ (jandyye@163.com,06liuhong@sina.com)
}

\begin{abstract}
As a form of socialist democratic politics, the importance of citizen participation is being increasingly attracted attention. The implementation of regional public management requires the participation and support of the citizens, and citizen participation has become an important feature in public management all over the world. The theoretical study and practical exploration of citizen participation in China started late, and lack of a complete theoretical system and operational measures, especially the lack of protection of citizens to participate in public affairs and public management. Therefore, the purpose of this paper is to define the concepts of citizen participation and regional public management, analyze the ways and domains that Chinese participation in public affairs. According to the exploration of the functions of citizen participation in China, summarize the citizen participation in the development of the regional public management.
\end{abstract}

Keywords: Citizens Participation, Regional Public Management, Development

\section{Introduction}

In the traditional period of administration, citizen participation is exclusive. The new theory of public management promotes citizen participation in order to ensure a higher degree of social equity, to provide the desired response for the formulation of public policy for the government. Only the construction of a service-oriented government can be the process of citizen participation to be better promote.

As a new model of development, public management is the social activities of public affairs management and the inevitable result of the historical development. Specifically, public management is that public organizations as the core of government, using the political, legal, economic, management theory and methods, for the purpose of effectively provide public goods and public services, to maximize the public interest. Using the public power democratically, formulating and implementation public policies with the scientific method in accordance with the law to manage the public affairs of the community provide public goods and public services. Therefore, the essential characteristics of public management are its public nature and serviceability. The implementation of public management requires the participation and support of the citizens. In a country, wide range of citizen participation is an integral part towards political democracy and political civilization integral is an effective way for citizens to enter the public domain and participate in public governance. Citizen participation can be conducive to enrich the contents of the public administration and ensure the realization of the public interest.

Sherry Arnstein in the study of American urban and regional planning, he made his famous A Ladder of Citizen Participation theory. Based on the different maturity and level of participation, she divided the effectiveness of citizen participation in the regional planning process into eight ladders, as follows: 


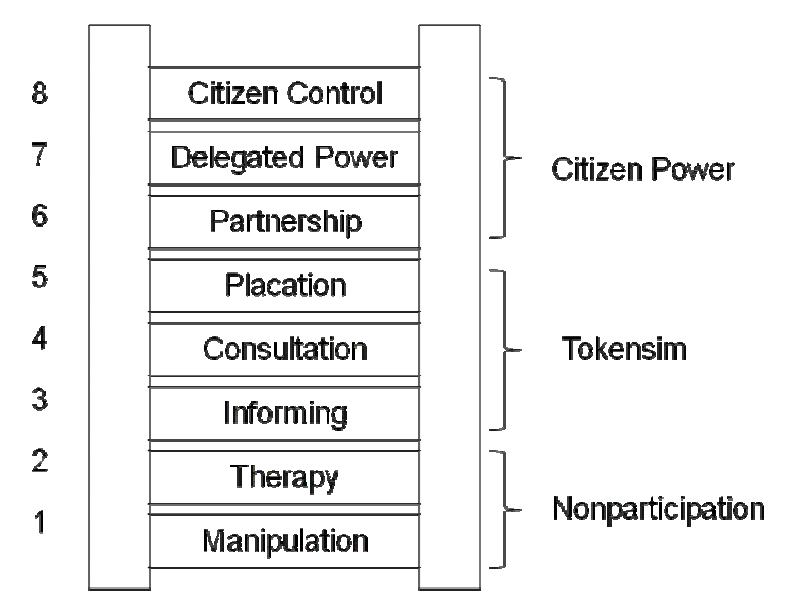

Figure 1 Eight rungs on the ladder of citizen participation ${ }^{(1)}$

From the case of China, with the continuous development of democratic politics and heightened awareness of citizen participation, citizens are no longer confined to the traditional field to participate in public affairs. In recent years, citizen participation is in the trend of the penetration and expansion of the regional public affairs; and the effectiveness of citizen participation in regional public affairs has been the transition to the information, advice and even cooperation stage.

\section{The Definition of Citizen Participation and Regional Public Management}

\subsection{The Definition of Citizen Participation}

Citizen participation is an activity that citizens involve or influence government public policy or public affairs through certain channels for participation. Sherry-Arnstein indicated that, "My answer to the critical what question is simply that citizen participation is a categorical term for citizen power. It is the redistribution of power that enables the have-not citizens, presently excluded from the political and economic processes, to be deliberately included in the future.”(1) Garson and William’s opinion toward citizen participation is that, "The citizen participation is an action. In the implementation and management of a program, the government provides the more channels for policy feedback in order to respond to public opinions, and people can participate in public affairs by a more direct way, as well as contact with the public offices.”(2)

\footnotetext{
(1) Sherry·Arnstein. A Ladder of Citizen Participation, Journal of American Institute of Planner, 1969

(2) Garson, Williams. Public Administration: Concept, Reading, Skill, Massachusetts: Allyn\&bacn, Inc. 1982
}

Citizen participation refers to the implementation of democratic politics, maximum and achievements of citizenship. This is an action that individual citizens or groups of citizens engaged in the pursuit of the public interest, including all public affairs and decisions. The government reflects public concerns and solves the people and the government conflict, to promote the legalization of public decision-making. This would be useful in improving the administrative capacity of the government. From the social level point of view, citizen participation is essentially a re-allocation and re-creation process of social resources. The concept of citizen participation develops to adapt to the needs of the democratic politics, is the inevitable requirement for the development of a democratic society.

\subsection{The Definition of Regional Public Management}

Region, is an objective existence and the concept of the abstract concept of space, it does not have strict scope, boundaries and the exact orientation. Any part of the Earth's surface, an area, a country or several countries can be seen as a region.

Regional public management is the plural subjects in the regions, taking the use of means and methods of negotiation and mediation within the lateral part of the region as well as regional and vertical level between cross-the overlapping relationship management, in order to solve public problems in one or more fields of the political, economic or society, to achieve common interests. Include the following: (1) the main body of the regional public management is of multiple subjects, including governments, the private organizations and the third sector; (2) the purpose of regional public management is to solve problems in economic, political or social fields; (3) the ways and means that regional 
public management use is not competition and suppression, but the negotiation and mediation based on the equal footing to achieve the optimal common interests; (4) the objects of regional public management are the individuals or groups in the region.

\section{Approaches of Citizen Participation in the Regional Public Management}

Citizen participation constraints of the contents and fields are generally in the regional public management. Different approaches can be used in different contents and scopes. Citizen participation in regional public management is mainly related to citizen participation in the formulation and implementation of public policy, citizen participation in local public goods provision and governance of local communities. Mainly form of Chinese citizens to participate in the regional public management including: election, villager autonomy, citizen participation in public decision-making and citizen oversight.

\subsection{Election}

The election is one of the most important forms of Chinese citizens to participate in public affairs. Election in China can be divided into two sorts: direct election and indirect election. Through elections, voters can express their interests and wishes. Through elections, public institutions can have a more accurate understanding of the preference of the voters, and then provide more effective services for citizens and society. Citizens within the institutional representative, can indirect participate in government behavior through elected representatives to compose the various Regional Congress, Congress, Parliament etc. These statutory representatives can help the citizens to gather the public issues of their concern to form the motion, the proposal, the suggestions during the government agenda.

\subsection{Villager Autonomy}

Chinese villagers' autonomy has gone through 20 years. The past 20 years, Chinese villagers' autonomy in terms of form or the content has been greatly enriched and developed. Formally, villager autonomy from the beginning of the development of the village committee election system to the villagers' representative meeting, village affairs system and other related systems. From a content point of view, it also gradually developed from the democratic elections to a full range of open system, including the democratic management democratic decision-making and democratic supervision. Practice has proved that the Chinese villagers' autonomy is an effective form of Chinese citizens to participate in the regional public management. It will have a profound impact on the democratic and scientific of public management in China.

\subsection{Citizen Participation in Public Decision-making}

In order to make the regional public management decision-making more realistic and in line with the interests and aspirations of citizens, China has created many new forms of citizen participation in public management from local to central government.

\subsubsection{Public Hearings}

The public hearing is a system of mediation, negotiation for public affairs and issues. Inviting relevant experts, and representatives of the people or general citizens to have open discussions and arguments on the policy, planning and decision-making involving the public interest and the interests of the citizens. Then gather the views of the public and interest groups.

\subsubsection{Worker Congress}

The majority of the Chinese state-owned enterprises have established a worker congress, to listen to the views of staff representatives of the major issues in the management of enterprises and institutions directly. This is an important form of Chinese state-owned enterprises practice democratic management.

\subsubsection{Establish a Think Tank}

In order to be more scientific in the regional public management, from the central to local levels, many governments have established a think tank, to absorb the experts to participate in decision-making, which both play the role of experts and reduce the subjectivity and arbitrariness in decision-making.

\subsubsection{Public Opinion Investigation}

The government gets to know the citizens' views and attitudes on policy issues or comments and suggestions on the quality of public services through a large-scale investigation or interviews. This is citizen participation sponsored by government.

\subsubsection{Citizen Conference}

The government invited citizens to participate in policy decision-making through the community meeting, to achieve the communication of political information, propaganda and mobilization, feedback, enhance understanding, and make policy recommendations target.

\subsection{Citizen Oversight}

Citizen oversight is one of the important driving forces in the development of regional public management and the major approach to the government oversight in China. 


\subsubsection{Citizen Complaints}

Citizen complaints refer to citizen complaints against a particular policy or services which damages their interests. It is a participation in order to solve the problem and restore equity. This kind of approach is citizen-initiated participation.

\subsubsection{Citizen Forum}

The citizen forum is the citizens spontaneously organized discussion on the management of public affairs and public issues. Collective learning and discussion of the citizens of a particular time, to enhance the understanding and acceptance of public policy. However, it requires a higher degree of culture and a strong sense of autonomy.

\subsubsection{Online Participation}

A new participatory approach, gathering various experts in the field and like-minded members of society, these people have had a wealth of information, they share the information by mutual exchange the information with other net friends. They are not only able to present their views, but also extensively solicit the views of others, to obtain the necessary information at any time.

\section{Citizen Participation in the Development of the Regional Public Management}

In recent decades, the practice of citizen participation in our regional public management has made great achievements, and the channels and means of civic participation have constantly enriched. The awareness and abilities of citizen participation continuously improve and the citizen participation system has begun to take into shape.

\subsection{Achievements of Citizen Participation in the Regional Public Management}

The practice of citizen participation started late and develops with the reform and opening up in China. Specially, in the 1990s, with the development of the practice of public management, social transformation accelerated, diversification of the main interests of the community, government management system have breakthroughs, urgently requires innovation of the government management concepts, practices, procedures, and system. However, when concern about the forms of citizen participation in our country, it is most base on the political participation and supply by the citizen participation in public affairs management.
Recently, the practice of citizen participation in the regional public management has shown a good momentum of development, and gained more reorganization by the general public. Undoubtedly, this will have a profound impact on advancing the development of China's democratic politics. However, we cannot deny that the relatively low level of productive in China, leads to the lower awareness and ability of citizen participation. The structures for citizen participation are not yet complete. The organizational foundation (Civil Society) for citizen participation is just started development. Therefore, the breadth and depth of our citizen participation are low in general. To sum up, the characteristics of our citizen participation show the following aspects: (1) Traditional System of Citizen Participation is Continuously Improvement; (2) Democratic Autonomy Has Made Great Progress; (3) The Political Participation of Non-governmental Organizations Has Become Increasingly Active; (4) Public Oversight System Has Drawn Greater Attention.

\subsection{Citizen Participation in the Development of the Regional Public Management}

In recent years, Chinese government has realized an important prerequisite of modern democratic politics is the civil society. The mature symbol of civil society is citizens' awareness to participate in politics. Citizen participation in regional public management is benefit to the construction of civil society, cultivate civic awareness, and enhance the political participation of citizens and to promote Chinese democratic political significance to the development.

\subsubsection{Citizen Participation Can Make Democratic and Efficient Public Policy}

In the process of public governance, active citizen participation allows the decision makers to make public policy more suitable with the reality of policy preferences of the citizens. Citizens can become thoughtful assessment of the government. The government can obtain a higher rate of public support. These will contribute to building a harmonious society which easy to manage with fewer differences and less struggle and regulation. Policy of citizen preferences in the implementation process, the public will have a positive attitude towards cooperation. Thus it would be benefit to reduce implementation costs and reduce the frustration of the people in the government, in terms of the government, positive citizen participation dispersing the pressure of the government reform. 


\subsubsection{Citizen Participation Can Effectively Prevent the Alienation of Power}

China adopted the "top-to-down" approach to reform. This is a special period of social transition. Because of the interests, a part of citizens take the use of unfair competition or power rent-seeking to gain private interests. This results in serious contradictions and conflict among different groups in society. In this case, in order to mobilize the power of the community is to form a civil society that everyone can involve in. Efficient civic participation is an important factor in the development of national democratic politics and to curb corruption at the maximum level.

\subsubsection{Citizen Participation Contribute to the Formation of a Good Political Culture}

Civil society is different from the political government as well as the market which pursuit for private interests. Civil society, once formed, they have the political culture and its core value of the idea that the spirit of a contract, a fair, just, justice, values, and the awakening of civic awareness. Citizen participation in politics can effectively guide the market economy when the market the pursuit for the maximum profit. The market would pay more attention to the fair and fair competition. This pursuit of economic value will determine the value-oriented political system. Accordingly, the value-oriented political system, in return, further reinforces the value of the pursuit of the direction in the economic field, thus forming a positive interaction between the markets, government, and society.

\section{Conclusions}

Citizen participation in regional public management achieves the democratic and scientific of public management, in line with the trend of social development. Citizen participation playing an important role in promoting the deepening administrative reform in China, the development of socialist democracy and build a socialist country under the rule of law, and a positive attitude toward the world in responding to the economy in the globalization.

The study of citizen participation in the regional public management is still at the beginning of China. Both theoretical aspects and the practice of citizen participation is at the exploratory stage. From the reality of our country, we should absorb the successful experiences in other countries, and then based on our national conditions to explore a suitable system for citizen participation and promote the further development of democratic politics in
China. Thus, to improve the government's public management quality, create the conditions for building a harmonious society.

\section{References}

[1] Chen Ruilian. Study of the origin and Development of Regional Public Management [J]. Political Studies, 2004, (1).

[2] Garson. Williams. Public Administration: Concept, Reading, Skill, Massachusetts: Allyn \& bacn, Inc. 1982.

[3] Guy • Peters. The Future Governance model of Government [M]. China People's University Press, 2001.

[4] Huang Guoman. The Analysis of Citizens' Political Participation [J]. Social Science Front, 2004, (3).

[5] John Krane, Democracy and Civil Society, Verso, Lnndou/ New York, 1988.

[6] Sherry • Arnstein. A Ladder of Citizen Participation, Journal of American Institute of Planner, 1969.

[7] Vivien Lowndes and Chris Skelcher: The Dynamics of Multi-Organizational Partnerships: An Analysis of Changing Modes of Governance, Public Administration, 1998.

[8] Wang Weiguo. Way of Citizens' Political Participation Orderly [M]. People's Publishing House, 2007.

[9] Wang Zheng. Regional Management and Development[M]. Beijing: Science Press, 2000.

[10] Yang Long. Regional Development and Regional Political Research in China [J]. Learning and Exploring, 2003 (4).

[11] Zhang Chengfu, Dang Xiuyun. Public Management [M]. Beijing: Press of Renmin University of China, 2001. 30.

[12] Zeng Jun. New Public Management theory: the System, Value and Tools [M]. Beijing: People's Publishing House, 2006. 